\title{
Vasoactive Drugs for Septic Shock: Where are we now?
}

\author{
Suzana Margareth Ajeje Lobo*, Joelma Villafanha Gandolfi and Marina Ajeje Lobo \\ Intensive Care Service, Hospital de Base de São José do Rio Preto, Faculdade de Medicina de São José do Rio Preto - São José do Rio Preto [SP], Brazil
}

Sepsis develops in about 750,000 people annually and accounts for more than 210,000 deaths per year in the United States [1]. Pediatric severe sepsis is also a burdensome public health problem, with prevalence, morbidity, and mortality rates similar to reports from critically ill adult populations [2]. In sepsis inflammatory mediators lead to circulatory abnormalities including peripheral vasodilatation, reduced mean arterial pressure (MAP), myocardial depression, and intravascular volume depletion [3]. With increased awareness and the use of protocolized care in the emergency department and in the intensive care unit (ICU) the mortality associated with sepsis has decreased significantly in the last decade in some countries $[4,5]$.

Hypovolemic, cardiogenic and obstructive forms of shock are characterized by decreased cardiac output, arterial pressure and profound vasoconstriction in the peripheral circulation. In vasodilatory shock, there is a complex interaction between pathologic vasodilation, relative and absolute hypovolemia, altered blood flow distribution, and myocardial depression [3]. Vasoactive drugs are the mainstay of hemodynamic management of vasodilatory shock when fluids fail to restore hemodynamics or to improve regional perfusion. It seems that that an optimal goal of MAP is 65 to $75 \mathrm{~mm} \mathrm{Hg}$ in patients with septic shock, but a higher MAP (75 to $85 \mathrm{~mm} \mathrm{Hg}$ ) may be preferable in patients with chronic arterial hypertension [6].

The Surviving Sepsis Campaign (SSC) launched in 2002 consists of management guidelines and performance improvement programs for adults with severe sepsis [7]. The second revision of the guidelines, published in 2012, is sponsored by 30 international scientific organizations [8]. According to the SSC recommendations, vasopressor agents should be initiated to raise the MAP to $65 \mathrm{~mm} \mathrm{Hg}$ if fluid resuscitation of $30 \mathrm{~mL} / \mathrm{kg}$ fails to achieve that goal.

Adrenergic agonists are the first-line vasopressors because of their rapid onset of action, high potency, and short half-life, which allows easy dose adjustment [9]. The SSC guidelines recommend norepinephrine as the first-choice vasopressor [8]. Norepinephrine is a potent $\alpha$-adrenergic agonist, and with modest $\beta$-adrenergic effects that help to maintain cardiac output. Administration of doses of 0.1 to $2.0 \mu \mathrm{g}$ per kilogram of body weight per minute generally results in a clinically significant increase in MAP, with little change in heart rate or cardiac output [9]. The delayed norepinephrine administration was found independently associated with hospital mortality in patients with septic shock in a recent report [10].

Dopamine, the immediate precursor of norepinephrine and epinephrine, is a less potent vasopressor with dose varying receptor binding [11]. The results of a meta-analysis had previously suggested that dopamine administration as compared with norepinephrine might be related to higher rates of death among patients with septic shock [12]. Indeed in a large, randomized, controlled, double-blind trial, dopamine had no advantage over norepinephrine as the first-line vasopressor agent [13]. In addition, more induced arrhythmias and was associated with increased mortality in patients with cardiogenic shock. Dopamine should be reserved for special situations such as patients with bradycardia and low risk of arrhythmias [8].

Relative vasopressin deficiency may be a contributor factor to vasodilatory septic shock. The Vasopressin and Septic Shock Trial (VASST) found no mortality benefit when comparing the addition of arginine vasopressin to norepinephrine versus norepinephrine alone [14]. However, post hoc analyses suggest that it may benefit patients with lower norepinephrine doses or those at risk for renal failure [14,15]. Arginine vasopressin 0.03 unit/minute may be added to norepinephrine with the anticipation of an effect equal to higher doses of norepinephrine alone [8]. Vasopressin should be administered only in patients with a high level of cardiac output and should not be used at doses higher than $0.04 \mathrm{U}$ per minute due to adverse effects such as elevated liver enzimes and serum bilirrubins, hyponatremia, mesenteric ischemia, skin necrosis and digital ischemia.

Dobutamine is a $\beta$-adrenergic agent that remains the 'gold standard' inotropic agent in the treatment of septic shock, regardless of whether norepinephrine is also being given [9]. Doses from 2.5 to $20 \mathrm{micrograms} / \mathrm{kg} / \mathrm{min}$ substantially increase cardiac output. A dose in excess of $20 \mu \mathrm{g}$ per kilogram per minute usually provides little additional benefit. Dobutamine may improve capillary perfusion in patients with septic shock, independent of its systemic effects [16]. Other inotropes such as phosphodiesterase type III inhibitors and levosimendan, a calcium sensitizer have inotropic and vasodilator activities, what limit its use in acute shock states.

Vasoplegia, as well as persistent and irreversible hypotension, is considered as a key factor leading to death due to refractory septic shock. Combination therapy with either epinephrine or vasopressin is used in patients who failed to increase MAP with norepinephrine alone [8]. Addition of epinephrine to norepinephrine in patients with septic shock unresponsive to fluid resuscitation improves hemodynamics, but may increase serum lactate and worse acidosis [17]. Vasopressin can be added to norepinephrine with the intent of achieving the target MAP. Another possible candidate for combination therapy is terlipressin that has selective V1 and V3 receptors action, and can be considered in septic patients with liver failure, portal hypertension and variceal bleeding [18].

Corticosteroid hormones play an important role in the control of vascular smooth muscle tone by potentiating vasoactive responses to catecholamine through glucocorticoid receptors. In addition relative adrenal insufficiency can occur in up to $70 \%$ of patients with septic shock [19]. Moderate doses of hydrocortisone improve sublingual capillary perfusion [20]. Hydrocortisone is recommended as an adjunctive therapeutic agent in patients with septic shock if adequate

*Corresponding author: Suzana Margareth Ajeje Lobo, Serviço de Terapia Intensiva do Hospital de Base da Faculdade de Medicina de São José do Rio Preto Avenida Brigadeiro Faria de Lima, 5.416, Zip code: 15090-000 - São José do Rio Preto [SP], Brazil, Tel: 1732015000; E-mail: suzana-lobo@uol.com.br

Received April 28, 2015; Accepted June 11, 2015; Published June 17, 2015

Citation: Lobo SMA, Gandolfi JV, Lobo MA (2015) Vasoactive Drugs for Septic Shock: Where are we now? Cardiol Pharmacol 4: 147. doi:10.4172/23296607.1000147

Copyright: () 2015 Lobo SMA. This is an open-access article distributed under the terms of the Creative Commons Attribution License, which permits unrestricted use, distribution, and reproduction in any medium, provided the original author and source are credited. 
Citation: Lobo SMA, Gandolfi JV, Lobo MA(2015) Vasoactive Drugs for Septic Shock: Where are we now? Cardiol Pharmacol 4: 147. doi:10.4172/23296607.1000147

Page 2 of 3

fluid resuscitation and vasopressor therapy are not able to restore hemodynamic stability at a dose of $200 \mathrm{mg}$ per day.

The following sets of care elements ('bundles') are to be completed within 3 and 6 hours from the patient's time of presentation to the emergency department, or within 3 and 6 hours of diagnosis on hospital wards or in the ICU (Figure 1). Adopters of the guidelines and bundles have already reported successful implementation with significant improvement in sepsis-bundle compliance and marked reduction in mortality [5].

\section{Acknowledgments}

The authors would like to thank Alexandre Lins Werneck for the careful English language review.

\section{References}

1. Angus DC, Linde-Zwirble WT, Lidicker J, Clermont G, Carcillo J, et al. (2001) Epidemiology of severe sepsis in the United States: analysis of incidence, outcome, and associated costs of care. Crit Care Med 29: 1303-1310.

2. Weiss SL, Fitzgerald JC, Pappachan J, Wheeler D, Jaramillo-Bustamante JC, et al. (2015) Global epidemiology of pediatric severe sepsis: the sepsis prevalence, outcomes, and therapies study. Am J Respir Crit Care Med 191: 1147-1157.

\section{Surviving Sepsis Campaign Care Bundles}

\section{To be completed with 3 hours}
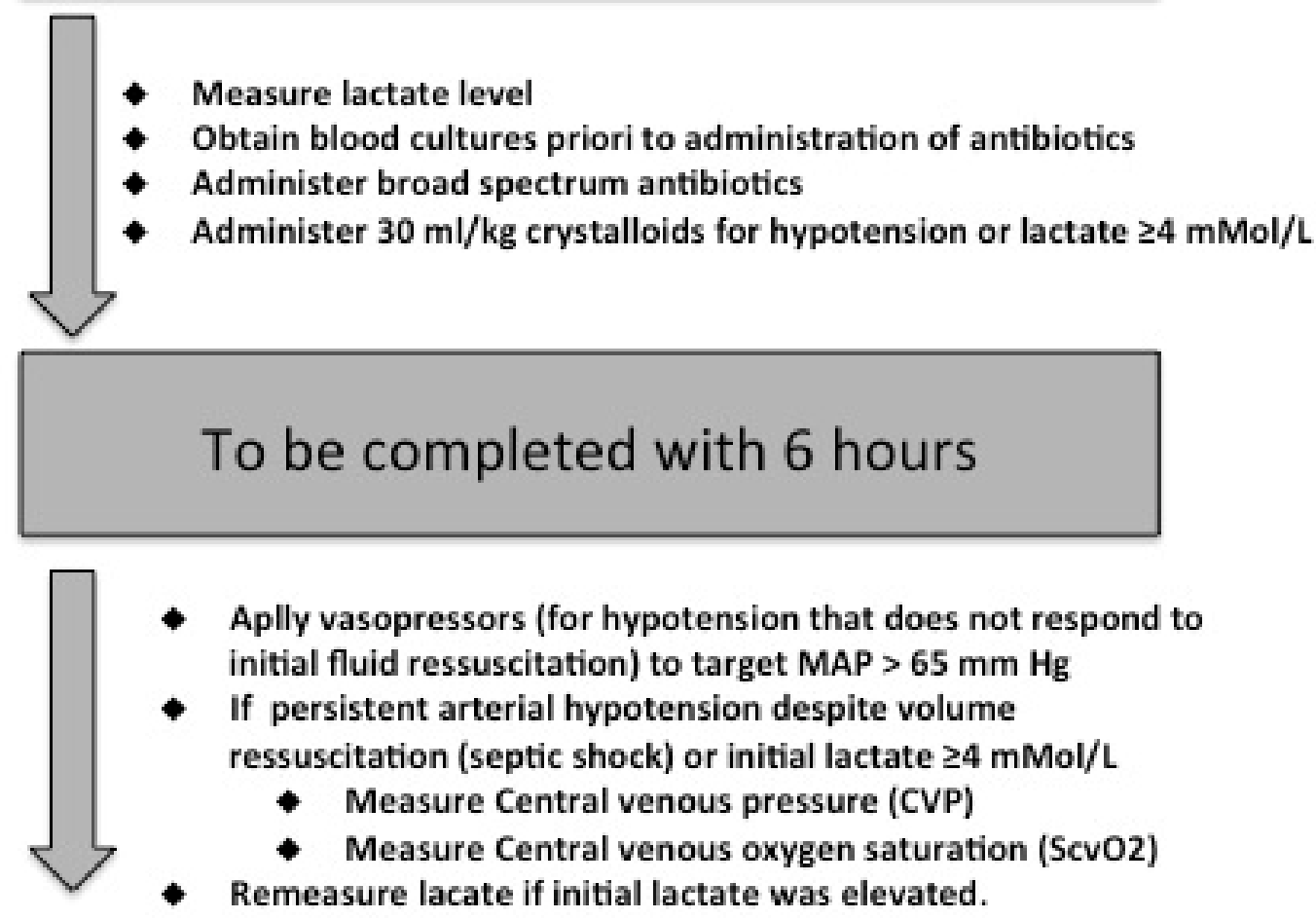

Figure 1: Surviving sepsis campaign care bundles. R.P. Dellinger, et al. Surviving Sepsis Campaign: international guidelines for management of severe sepsis and septic shock, 2012. 
Citation: Lobo SMA, Gandolfi JV, Lobo MA (2015) Vasoactive Drugs for Septic Shock: Where are we now? Cardiol Pharmacol 4: 147. doi:10.4172/23296607.1000147

Page 3 of 3

3. Hotchkiss RS, Karl IE (2003) The pathophysiology and treatment of sepsis. N Engl J Med 348: 138-150.

4. Stoneking L, Denninghoff K, Deluca L, Keim SM, Munger B (2011) Sepsis bundles and compliance with clinical guidelines. J Intensive Care Med 26: 172-182.

5. Miller RR, Dong L, Nelson NC, Brown SM, Kuttler KG, et al. (2013) Multicenter implementation of a severe sepsis and septic shock treatment bundle. Am J Respir Crit Care Med 188: 77-82.

6. Leone M, Asfar P, Radermacher P, Vincent JL, Martin C (2015) Optimizing mean arterial pressure in septic shock: a critical reappraisal of the literature. Crit Care 19: 101.

7. Dellinger RP, Carlet JM, Masur H, et al. (2004) Surviving Sepsis Campaign guidelines for management of severe sepsis and septic shock. Crit Care Med 32: $858-873$

8. Dellinger RP, Levy MM, Rhodes A, Annane D, Gerlach H, et al. (2013) Surviving sepsis campaign: international guidelines for management of severe sepsis and septic shock: 2012. Crit Care Med 41: 580-637.

9. Vincent JL, De Backer D (2013) Circulatory shock. N Engl J Med 369: 17261734.

10. Bai X, Yu W, Ji W, Lin Z, Tan S, et al. (2014) Early versus delayed administration of norepinephrine in patients with septic shock. Crit Care 18: 532.

11. Stanchina ML, Levy MM (2004) Vasoactive drug use in septic shock. Semin Respir Crit Care Med 25: 673-681.

12. De Backer D, Aldecoa C, Njimi H, Vincent JL (2012) Dopamine versus norepinephrine in the treatment of septic shock: a meta-analysis*. Crit Care Med 40: 725-730.

13. De Backer D, Biston P, Devriendt J, Madl C, Chochrad D, et al. (2010) Comparison of dopamine and norepinephrine in the treatment of shock. N Engl J Med 362: 779-789.

14. Russell JA, Walley KR, Singer J, Gordon AC, Hébert PC, et al. (2008) Vasopressin versus norepinephrine infusion in patients with septic shock. N Engl J Med 358: 877-887.

15. Gordon AC, Russell JA, Walley KR, Singer J, Ayers D, et al. (2010) The effects of vasopressin on acute kidney injury in septic shock. Intensive Care Med 36: 83-91.

16. De Backer D, Creteur J, Dubois MJ, Sakr Y, Koch M, et al. (2006) The effects of dobutamine on microcirculatory alterations in patients with septic shock are independent of its systemic effects. Crit Care Med 34: 403-408.

17. Myburgh JA, Higgins A, Jovanovska A, Lipman J, Ramakrishnan N, et al. (2008) A comparison of epinephrine and norepinephrine in critically ill patients. Intensive Care Med 34: 2226-2234.

18. Morelli A, Ertmer C, Lange M, Dünser M, Rehberg S, et al. (2008) Effects of short-term simultaneous infusion of dobutamine and terlipressin in patients with septic shock: the DOBUPRESS study. Br J Anaesth 100: 494-503.

19. Annane D, Sébille V, Charpentier C, Bollaert PE, François B, et al. (2002) Effect of treatment with low doses of hydrocortisone and fludrocortisone on mortality in patients with septic shock. JAMA 288: 862-871.

20. Buchele GL, Silva E, Ospina-Tascon GA, Vincent JL, de Backer D (2009) Effects of hydrocortisone on microcirculatory alterations in patients with septic shock. Crit Care Med. 37:1341-1347. 